\title{
Engineering Characterization of Hot-Mix Asphalt in Western Australia
}

\author{
Ainalem Nega ${ }^{1}$, Hamid Nikraz ${ }^{2}$ and Colin Leek $^{3}$ \\ ${ }^{1}$ PhD Candidate, Department of Civil Engineering, Curtin University, GPO Box \\ U1987, Perth, WA 6845, Australia; Tel: (+61) 8 9266-2674; Fax: (+61) 8 9266- \\ 2681; Email: Ainalem.Nega@curtin.edu.au \\ ${ }^{2}$ Professor, Head of Department of Civil Engineering, Curtin University, GPO Box \\ U1987, Perth, WA 6845, Australia; Tel: (+61) 8 9266-7573; Fax: (+61) 8 9266-2681; \\ Email: H.Nikraz@curtin.edu.au \\ ${ }^{3}$ Adjunct Professor, Department of Civil Engineering, Curtin University, GPO Box \\ U1987, Perth, WA 6845, Australia; Tel: (+61) 8 9266-4761; Fax: (+61) 8 9266-2681; \\ Email: $\underline{\text { C.Leek@ curtin.edu.au }}$
}

\begin{abstract}
The use of full depth asphalt pavement to construct and rehabilitate heavily loaded urban roads that has grown rapidly in Western Australia over the past 3 years. Five different types of asphalt mixes were produced in the laboratory according to the Australian Standard methods of sampling and testing asphalt to modify payment performance mixture. The main role of this research is to evaluate and assess the hotmix asphalt pavement performance characteristic for Western Australia road. In this study, laboratory test for tensile strength, resilient modulus, wheel tracking, asphalt binder content and Marshall Compaction test were taken and analyzed to each asphalt mixtures. Results showed that AC20-75 and AC14-75 Blow asphalt mixes were more efficient and effective in pavement performance as compared to the other mixes. In general, all the asphalt mixes that are used in this study can strength and stable the mixture stiffness of asphalt that is notable. The modification effect rank can be described as AC20-75 Blow > AC14-75 Blow > AC14-50 Blow > AC7-50 Blow > SMA7-50 Blow in this research.
\end{abstract}

Author keywords: Characteristic; asphalt mixture; hot-mix asphalt; tensile strength; resilient modulus; wheel tracking; asphalt binder content; Marshall compaction; Western Australia

\section{Introduction}

The use of full depth asphalt pavements to construct and rehabilitate heavily loaded urban roads has rapidly grown in Western Australia (WA) over the past 3 years. There is limited data available from testing carried out by the Mainroads about the characteristics and variability of WA asphalt mixes. Although some data is available from testing carried out by others on Mainroads contracts, but it also would be necessary to determine whether Mainroads WA owns this data and has the right to publish the data so that it can be used to predict the likely performance of WA full depth asphalt pavements.

Hot-mix asphalt is known by many different names: HMA, asphaltic concrete, plant mix, bituminous mix, bituminous concrete, and many others (Gillespie et al. 1992) . It is a combination of two primary ingredients - aggregates and asphalt binder. The 
aggregates total approximately $95 \%$ of the total mixture by weight. They are mixed with approximately 5\% asphalt binder to produce HMA (Gillespie et al. 1992). Hot and cold asphalt mixes are comprised of two major materials: aggregates (i.e. mixture of sand, gravel, crushed stone, slag and mineral filler) and asphalt cement (crude oil, hydrated lime and dust) as discussed on literature by (ACIC2007; Mrawira \& Luca 2006). Bitumen had been defined by various sources as crude oil with a dynamic viscosity at reservoir conditions more than 10,000 centipoise (AASHTO1986; ACIC2007).

The asphalt concrete or hot mix asphalt (HMA) is the one the most widely used infrastructure materials for road construction. Hot mix asphalts can be described as a multiphase heterogeneous material composed of a viscoelastic asphalt binder, irregular rigid aggregate particle in high volume fraction, and small percentage of air voids (Gopalakrishnan \& Kim 2011). These component materials exhibiting various properties contribute to complex mechanical behavior of HMA, which can be characterized as viscoelasticity, and plastic under different condition such as temperature, load application and aging (Dibike et al. 2001). Therefore, the mechanical behavior of hot mix asphalt should be understood by not only the individual properties of HMA components, but also by considering asphalt binder and aggregate acting together.

The goal of this study is to evaluate and assess the engineering chacteristics of hotmix asphalt using a laboratory tests so that data can be used to predict the likely performance of Western Australia full depth asphalt pavement. Figure 1 shows the different types of asphalt mixes in this study.

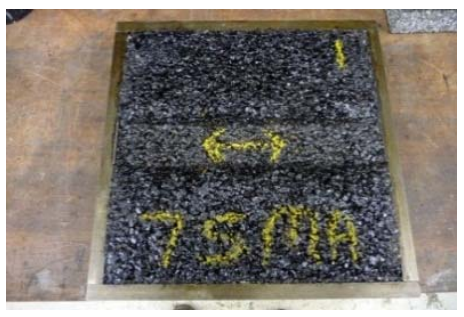

(a) SMA7-50 Blow

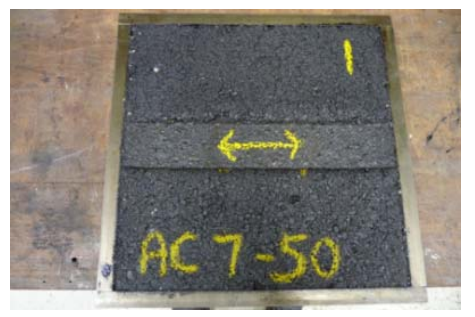

(b) AC7-50 Blow

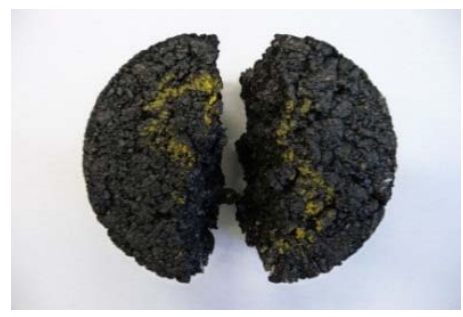

(c) AC14-50 Blow

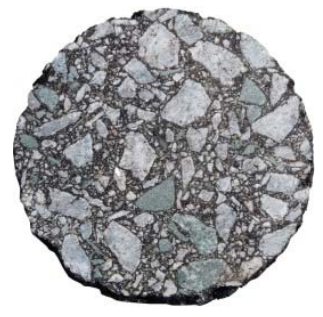

(d) AC14-75 Blow

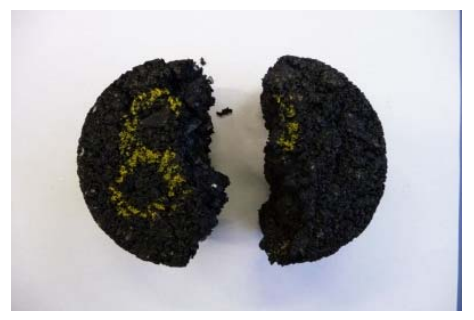

(e) AC20-75 Blow

Figure 1: Types of asphalt mixes during the laboratory tests 


\section{Materials and Methods}

\subsection{Materials}

Types of hot mixed asphalt used on the Mainroads WA network are dense graded asphalt (DGA), open graded asphalt (OGA) and stone mastic asphalt (SMA). DGA, the most common type of asphalt, provides optimal structure strength and generally good resistance to deformation. OGA is designed to drain water through the asphalt to remove excess water from the tyre/road surface. SMA is similar to OGA but has a high proportion of dust and high binder contents to achieve an improved fatigue life. SMA has a texture surface but does not drain water through its layer as does OGA (ACIC2007; Brown, Kandhal \& Zhang 2004; MRWA2007). All Materials selected for this project were from local sources and are indigenous of Western Australian pavement materials used in the industry.

\subsection{Methods}

The design method specified by Mainroads Western Australia is the Marshall method of mix design. The aim of the method is to satisfy specified design criteria. The descriptions of asphalt mixes design are as following:

- SMA7-50 blow: thickness of $7 \mathrm{~mm}$ granite stone mastic asphalt (SMA)

- AC7-50 blow: thickness of $7 \mathrm{~mm}$ open graded granite

- AC14-50 blow: thickness of $14 \mathrm{~mm}$ dense graded granite (intersection mix)

- AC14-75 blow: thickness of $14 \mathrm{~mm}$ dense graded granite (intermediate mix)

- AC20-75 blow: thickness of $20 \mathrm{~mm}$ dense graded granite (intermediate mix)

During individual asphalt mixes run, specimens were taken and assessed in different categories of asphalt mixes. Asphalt mixes specimens were subjected to the laboratory tests: tensile strength (TSR), resilient modulus, wheel tracking, asphalt binder content and Marshall Compaction test.

The bulk specific gravity test was performed after samples had cooled to room temperature according to the Australian Standard Testing Method AS 2891. Air voids were calculated using bulk specific gravity and maximum theoretical specific gravity data. Three specimens for each asphalt mix were tested as per Australian Standard. Specimens were placed in a water bath at $60^{\circ} \mathrm{C}$ for a period of $30 \mathrm{~min}$ and were tested for Marshall Stability and flow. The details methods of sampling and testing of hotmix asphalt in Australian Standard Testing Method are shown in Table 1.

Table 1: Methods of sampling and testing asphalt in Australian Standard Test Method (Austroads 1992; Austroads 2006; Austroads 2008)

\begin{tabular}{|l|c|c|}
\hline Type of Mix & Material Test & Test Method \\
\hline SMA7-50 Blow & Tensile strength ratio & AGPT/T232 \\
\hline AC7-50 Blow & Resilient modulus & AS 2891.13.1 \\
\hline AC14-50 Blow & Wheel tracking & AGPT/T231 \\
\hline AC14-75 Blow & Asphalt binder content & AS 2891.1.1 \\
\hline AC20-75 Blow & Marshall compaction & AS 2891.9.3 \\
\hline
\end{tabular}




\section{Engineering Characterization of Asphalt Mixes}

\subsection{Tensile Strength Ratio}

A variety of test have been used that attempt to identify the moisture sensitivity and binder stripping potential of asphalt mixes. The test was carried out according to AASHTO T283 (commonly known as the Modified Lottman Test) specification by loading a Marshall specimen with compressive loading acting parallel to and along the vertical diametric-loading plane (AASHTO1986). The ratio of the tensile strength of the water-conditioned specimens to that of dry specimens is the tensile strength ratio. Tensile strength ratio (TSR) of asphalt mixes is an indicator of their resistance to moisture suitability In Australia, the development and implication of practical fundamental and simulative tests for characterization potential of asphalt mixestensile strength ratio test has implemented on AG:PT/T232, adapted from ASTM D 4867-92 (Austroads 2008).

\subsection{Resilient Modulus}

The resilient modulus is defined as a ratio of the deviator stress to the recoverable strain. It is known that the bituminous material is not elastic, but it experiences some permanent deformation after each load application (Jahromi \& Khodaii 2009). Resilient modulus of pavement material is an important material property in any mechanistically based design/analysis procedure for flexible pavements (FHWA2002). The resilient modulus $\left(M_{R}\right)$ is the material property required for the 1993 American Association of State Highway and Transportation Officials (AASHTO) Design Guide, which is an empirically based design procedure, and is the primary material input parameter for the 2002 Design Guide (AASHTO1993).

\subsection{Wheel Tracking}

Australia initially adopted the dynamic creep test as the preferred method of determining the rut resistance of asphalt mixtures (Austroads 2008). Currently, wheel tracking is selected as the most suitable test method for measuring the rut resistance of asphalt mixtures (Olive \& Alderson 1995a). The wheel tracking test consists of a loaded wheel assembly and a confined mould in which a $300 \times 300 \times 200 \mathrm{~mm}$ specimen of asphalt mix is rigidly restrained on its four sides. A motor and a reciprocating device provide the forward and backward motion to the wheel at the rate of 24 passes per minute along the length of the slab. The temperature during the test is maintained by a water bath over and around the mould.

\subsection{Asphalt Binder Content}

The flexural stiffness and fatigue life of asphalt also influence by the binder volume (film thickness) and compaction level (air void) achieved in the mix. The combined effect of binder content and air voids in a mix in the form of percent voids filled binder (VFB) has also been considered as an useful parameter in the fatigue life predication models (Harvey et al. 1995; Said 1997; SHRP1994b). Santucci (1977) applied a correction factor to estimate the fatigue lives of mixes with binder and air void contents other than the mixes with $\mathrm{V}_{\mathrm{b}}=11 \%$ and $\mathrm{V}_{\mathrm{a}}=5 \%$, evaluated controlled stress fatigue tests. 


\subsection{Marshall Compaction of Hot-Mix Asphalt Pavement}

The compaction process has a great effect on the strength and durability of hot-mix asphalt pavements. The main objective of pavement compaction is to achieve an optimum density. This helps to ensure that pavement will have the necessary bearing capacity to support the expected traffic loads and durability to withstand weathering (Chadbourn et al. 1996). The goal of compaction is to achieve the optimum air void content and compressing the coated stones together by increasing the density of the mix to the considered level of compaction with a minimum change in the gradation and structure (Airey et al. 2008; Pourtahmasb \& Karim 2010).

Recent laboratory studies have shown that the compaction can highly affect the performance of the hot-mix asphalt (HMA) and stone mastic asphalt (SMA) mixtures (Khan et al. 1998; Linden, Mahoney \& Jackson 1992). Inappropriate compaction may draw the binder to the surface of HMA and SMA causing flushing of the surface and loss of texture or aggregate segregation (Pourtahmasb \& Karim 2010). California kneading compactor, Gyratory compactor and Marshall Hammer are being used as SMA compactors due to mix design method (Khan et al. 1998).

\section{Results}

A summary of average tensile strength ratio of dry and moisture condition is shown in Table 2. From the data presented, it can be seen that the AC7-50 blow asphalt mix has generally had high TSR of $112.9 \%$ as compared to other asphalt mixes. AC20-75 blow was the second best to have nearly reached a TSR of AC7-50 blow. This showed that the asphalt mixes are non-moisture susceptible. SMA7-50, AC14-50 and AC14-75 blow asphalt mixes had also relatively low as compared to AC7-50 and AC20-75 blow asphalt mixes but both of them are not susceptible to moisture. According to AASHTO T283,"Resistance of Compacted Bituminous Mixture to Moisture Induced Damage", the design asphalt mixture is judged to be non-moisture susceptible if it has a TSR greater than 80 percent (Airey et al. 2008; AASHTO2000; Apeagyei, Buttlar \& Dempsey 2006).

The average resilient modulus for different types of asphalt mixes is given in Table 3 and Figure 2. As it can be seen from the results, AC20-75 blow asphalt mix had high resilient modulus of 6824 MPa (Figure 2). However, SMA7-50 and AC7-50 blow asphalt mix had poor resilient modulus of 3713 and $4618 \mathrm{MPa}$, respectively (Figure 2). It is clear that asphalt mix that has low resilient moduli do tend to contribute to low plasticity, low group index, high silt content, low clay content, low specific gravity, and high organic contents. Hicks and Monismith (1981) stated that the resilient modulus of partially crushed aggregate decreased with an increase in fine contents, while the modulus increased for crushed aggregate with increasing in fine content. The total recovered strain (Figure 3), rise time and temperature (Table 3) of the resilient modulus test for each asphalt mixes are similar. This showed that the resilient modulus is based up within the determination of Australian Standard.

The average wheel tracking test for different types of asphalt mixes is shown in Figure 4. The analyses indicated that AC20-75 blow asphalt mix had low rut depth of $1.9 \mathrm{~mm}$ as compared to other asphalt mixes. AC14-75 blow was the second in rank 
with a rut depth of $2.4 \mathrm{~mm}$. This showed that these asphalt mixes are high rut resistance of asphalt mixture and less to pavement distress and asphalt fatigue cracking. However, the rut depth observed for SMA7-50 blow was $15 \mathrm{~mm}$ after 8, 452 cycles while $5 \mathrm{~mm}$ and $4.2 \mathrm{~mm}$ for AC7-50 blow and AC14-50 blow after 10,000 cycles, respectively. This indicated that SMA7-50 blow asphalt mix has high pavement distress and low rut resistance of asphalt mixture. There was also a sudden steep change in slope after 8,000 cycles for SMA7-50 blow. This may be attributed to the stripping of aggregate. No stripping was however, observed after 10, 000 cycles to other asphalt mixes.

A summary of asphalt binder content for different types of asphalt mixes is shown in Figure 5. The results indicated that AC14-75 and A20-75 blow property of asphalt mix had low percentage of binder content of $4.7 \%$ and $4.3 \%$ in the given order. This showed that AC14-75 and AC20-75 blow asphalt mixes might have increased the frictional contact between aggregate particle and the overall stiffness and stability of the asphalt mixes as compared to other asphalt mixes. However, SMA7-50, AC7.50 and AC14-50 blow asphalt mixes had high percentage of binder content. This showed that increase in binder content reduce the frictional contract between aggregate particles. Beyond a certain value, further increases in binder content reduce the frictional contact between aggregate particles and the overall stiffness and stability of the asphalt (Austroads 2006). At low percentages, added binder content increases the mix cohesion and strength (Anderson, Walker \& Turner 1999).

Average Marshall Compaction stability and Marshall Compaction flow for different types of asphalt mixes are shown in Figure 6 and 7. As it can be seen from the analyses, AC20-70 blow asphalt mix had high stability of $16 \mathrm{kN}$ (Figure 6) as compared to other asphalt mixes. AC7-50, AC14-50 and AC14-75 blow asphalt mix had a similar strength and stability of $15.1 \mathrm{kN}$. This indicated that the asphalt mixes pavement will have the necessary bearing capacity to support the expected traffic loads and durability to withstand weathering. Marshall Compaction flow rate for AC20-75 blow was less as compared to other asphalt mixes (Figure 7). However, SMA7-50 blow had poor strength and stability and high Marshall Compaction flow of $5.3 \mathrm{~mm}$, and can highly affect the pavement performance. Recent laboratory studies have shown that the compaction can highly affect the performance of the hot-mix asphalt mixtures (Linden, Mahoney \& Jackson 1992; Pourtahmasb \& Karim 2010).

\section{Conclusions}

The pavement materials performance for strength and durability of hot mix asphalt mixtures was assessed and analyzed using the engineering characteristics and variability of flexible pavement for Western Australia roads in laboratory tests.

The comparison of the different types of asphalt mixes using a standard tests methods and techniques revealed that an AC20-75 blow and AC14-75 blow asphalt mix are the most efficient and effective in all categories of engineering characterization and variability of asphalt performance measures for strength and durability as compared to other asphalt mix. 
In general, all the asphalt mixes that are used in this research study can strength and stable the mixture stiffness of asphalt that is notable. The modification effect rank can be described as AC20-75 Blow > AC14-75 Blow > AC14-50 Blow > AC7-50 Blow > SMA7-50 Blow in this research.

Table 2: Tensile strength (dry and moisture) for different types of asphalt mixes

\begin{tabular}{|c|c|c|c|c|c|c|}
\hline \multicolumn{9}{|c|}{ Moisture Sensitivity } \\
\hline \multirow{2}{*}{ Rank } & \multirow{2}{*}{ Mix } & Tensile strength (kPa) & \multirow{2}{*}{ TSR } & \multicolumn{2}{|c|}{ Air void ratio (\%) } \\
& & Dry & Moisture & & Dry & Moisture \\
\hline $\mathbf{3}$ & SMA7 - 50 Blow & 686.9 & 626.6 & 91.2 & 8.0 & 7.9 \\
\hline $\mathbf{1}$ & AC7 - 50 Blow & 831.5 & 938.7 & 112.9 & 8.2 & 8.3 \\
\hline $\mathbf{4}$ & AC14 - 50 Blow & 990.4 & 894.8 & 90.3 & 8.4 & 8.2 \\
\hline $\mathbf{5}$ & AC14 - 75 Blow & 1225.5 & 995.7 & 81.2 & 8.3 & 8.5 \\
\hline $\mathbf{2}$ & AC20 - 75 Blow & 995.4 & 1024.8 & 103 & 7.8 & 7.4 \\
\hline
\end{tabular}

Table 3: Resilient modulus for different types of asphalt mixes

\begin{tabular}{|c|c|c|c|c|c|c|c|}
\hline \multicolumn{7}{|c|}{ Resilient Modulus Results } \\
\hline Mix Type & $\begin{array}{c}\text { Specimen } \\
\text { No. }\end{array}$ & $\begin{array}{c}\text { Force } \\
(\mathbf{N})\end{array}$ & $\begin{array}{c}\text { Total } \\
\text { Recovered } \\
(\boldsymbol{\mu})\end{array}$ & $\begin{array}{c}\text { Rise } \\
\text { time } \\
(\mathbf{m s})\end{array}$ & $\begin{array}{c}\text { Load } \\
\text { time } \\
(\mathbf{m s})\end{array}$ & $\begin{array}{c}\text { Resilient } \\
\text { modulus } \\
(\mathbf{M P a})\end{array}$ & $\begin{array}{c}\text { Temp } \\
\left({ }^{\circ} \mathbf{C}\right)\end{array}$ \\
\hline \multirow{2}{*}{$\begin{array}{c}\text { SMA7 - } \\
\text { 50 Blow }\end{array}$} & 1 & 717.8 & 48.5 & 40.0 & 138.8 & 1525.0 & 24.8 \\
\cline { 2 - 8 } & 2 & 1846.8 & 52.7 & 36.0 & 121.2 & 3600.0 & 24.6 \\
\cline { 2 - 8 } & 3 & 1942.1 & 52.1 & 36.8 & 119.8 & 3825.0 & 24.5 \\
\hline AC7 - & 1 & 2627.1 & 54.2 & 38.0 & 121.4 & 5019.0 & 25.1 \\
\cline { 2 - 8 } $\mathbf{5 0 ~ B l o w ~}$ & 2 & 2120.3 & 51.9 & 36.4 & 118.0 & 4223.0 & 25.3 \\
\cline { 2 - 8 } & 3 & 2338.0 & 52.3 & 36.6 & 117.6 & 4615.0 & 25.1 \\
\hline AC14- & 1 & 2694.6 & 52.1 & 39.8 & 122.8 & 5337.0 & 25.1 \\
\cline { 2 - 8 } $\mathbf{5 0}$ Blow & 2 & 2577.8 & 54.0 & 40.2 & 123.6 & 4921.0 & 24.8 \\
\cline { 2 - 8 } & 3 & 1315.1 & 53.0 & 35.2 & 127.6 & 2584.0 & 24.9 \\
\hline AC14- & 1 & 2902.7 & 52.1 & 39.0 & 122.0 & 5630.0 & 24.8 \\
\cline { 2 - 8 } & 2 & 2831.8 & 48.3 & 37.2 & 119.8 & 5959.0 & 25.2 \\
\cline { 2 - 8 } & 3 & 2865.5 & 52.1 & 36.8 & 119.8 & 5576.0 & 24.8 \\
\hline AC20 - & 1 & 3244.2 & 48.8 & 45.6 & 133.6 & 6991.0 & 24.9 \\
\cline { 2 - 8 } & 2 & 3301.9 & 51.2 & 39.0 & 119.8 & 6794.0 & 24.6 \\
\cline { 2 - 8 } & 3 & 3361.7 & 52.0 & 42.2 & 123.6 & 6688.0 & 24.5 \\
\hline
\end{tabular}




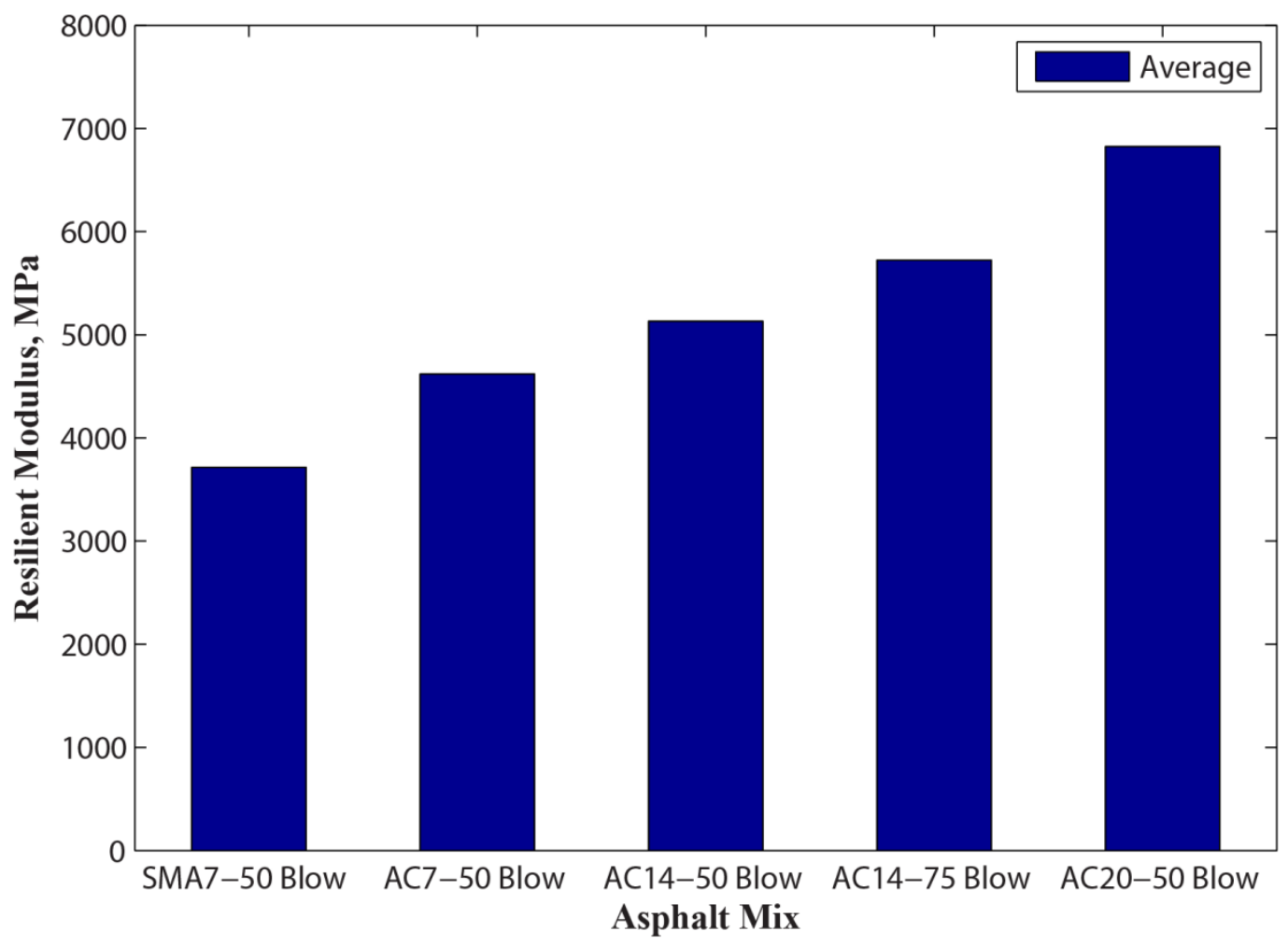

Figure 2: Average resilient modulus (air voids) for different types of asphalt mixes

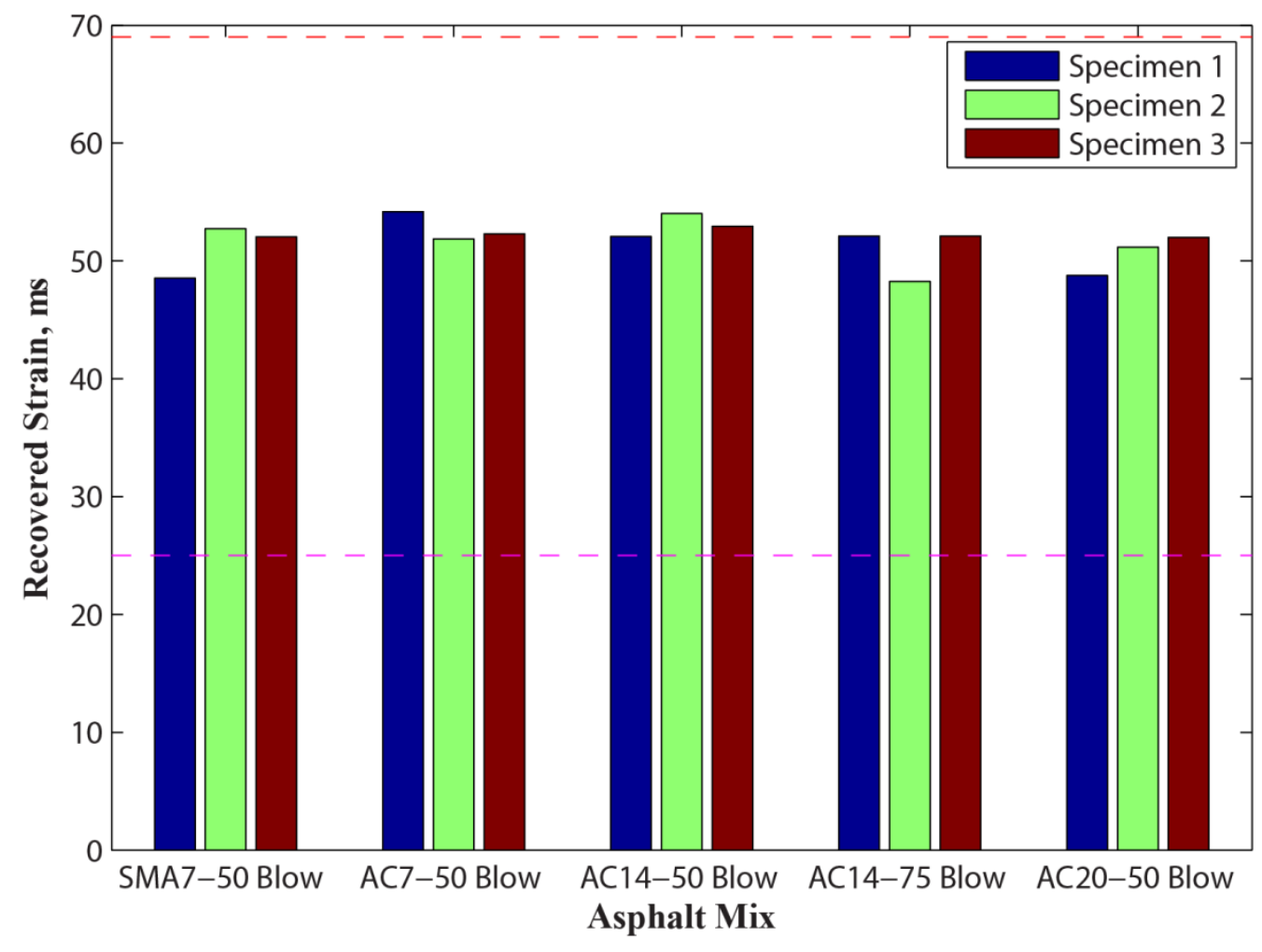

Figure 3: Resilient modulus (recovered strain) for different types of asphalt mixes 


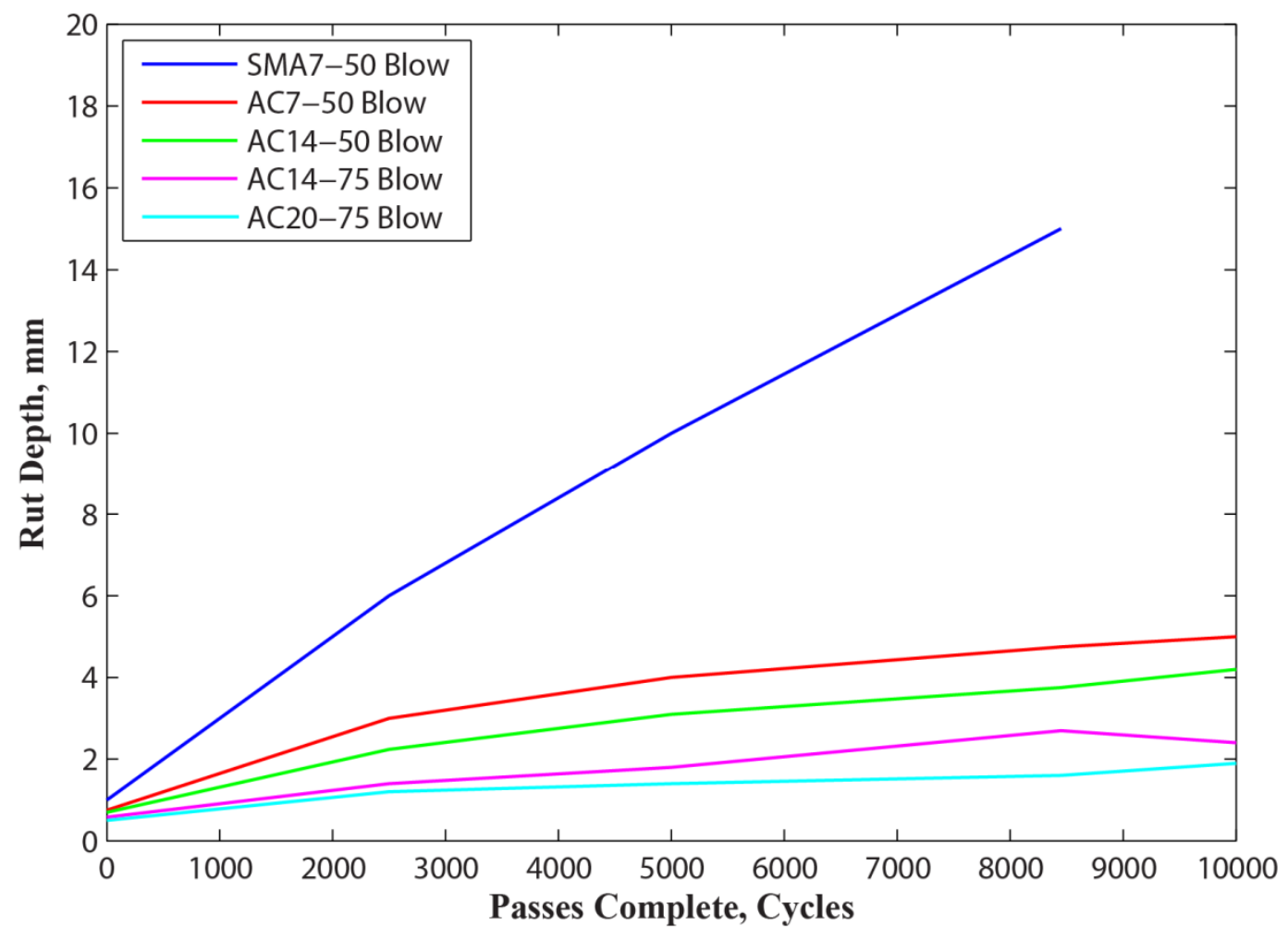

Figure 4: Average wheel tracking tests for different types of asphalt mixes

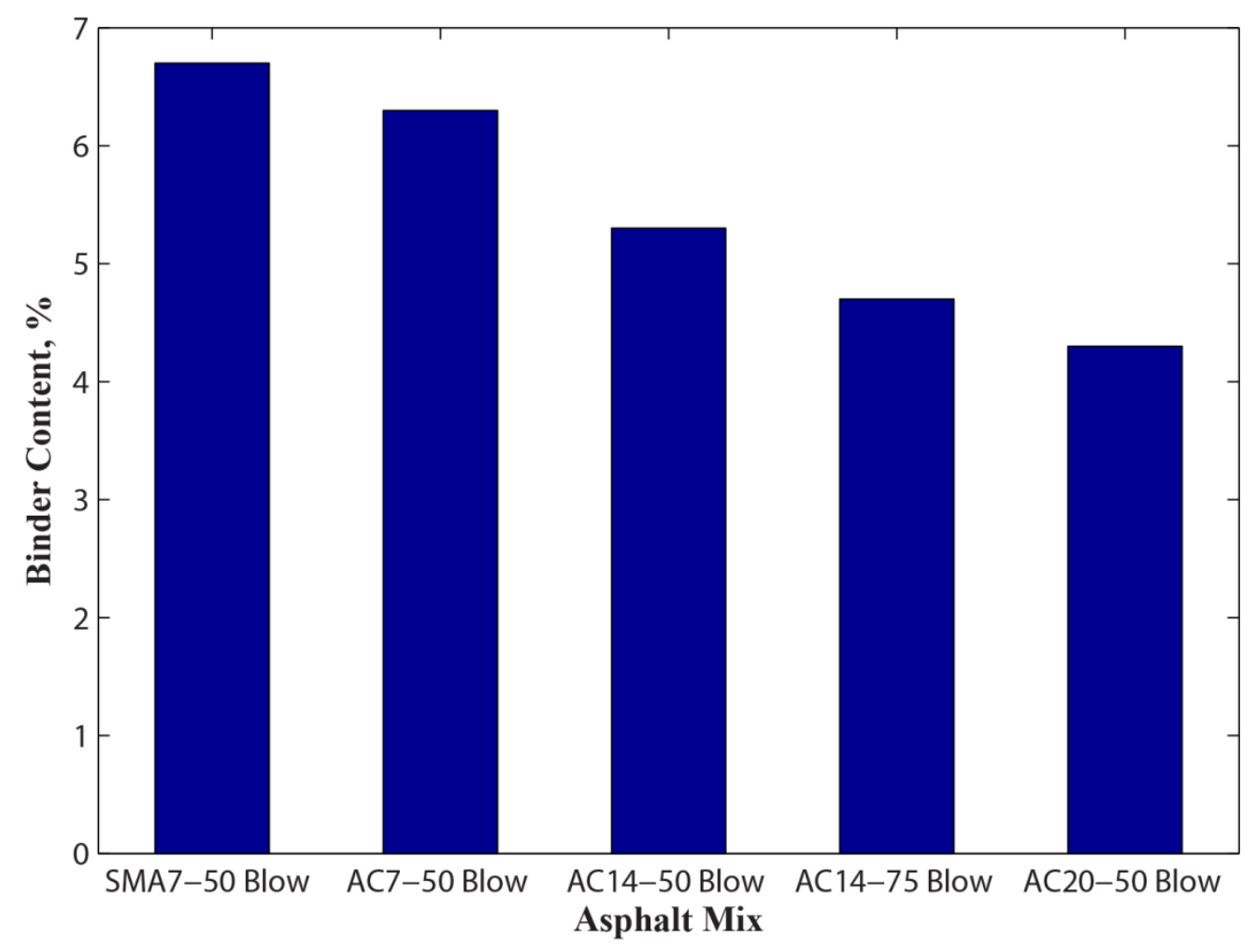

Figure 5: Asphalt binder content for different types of asphalt mixes 


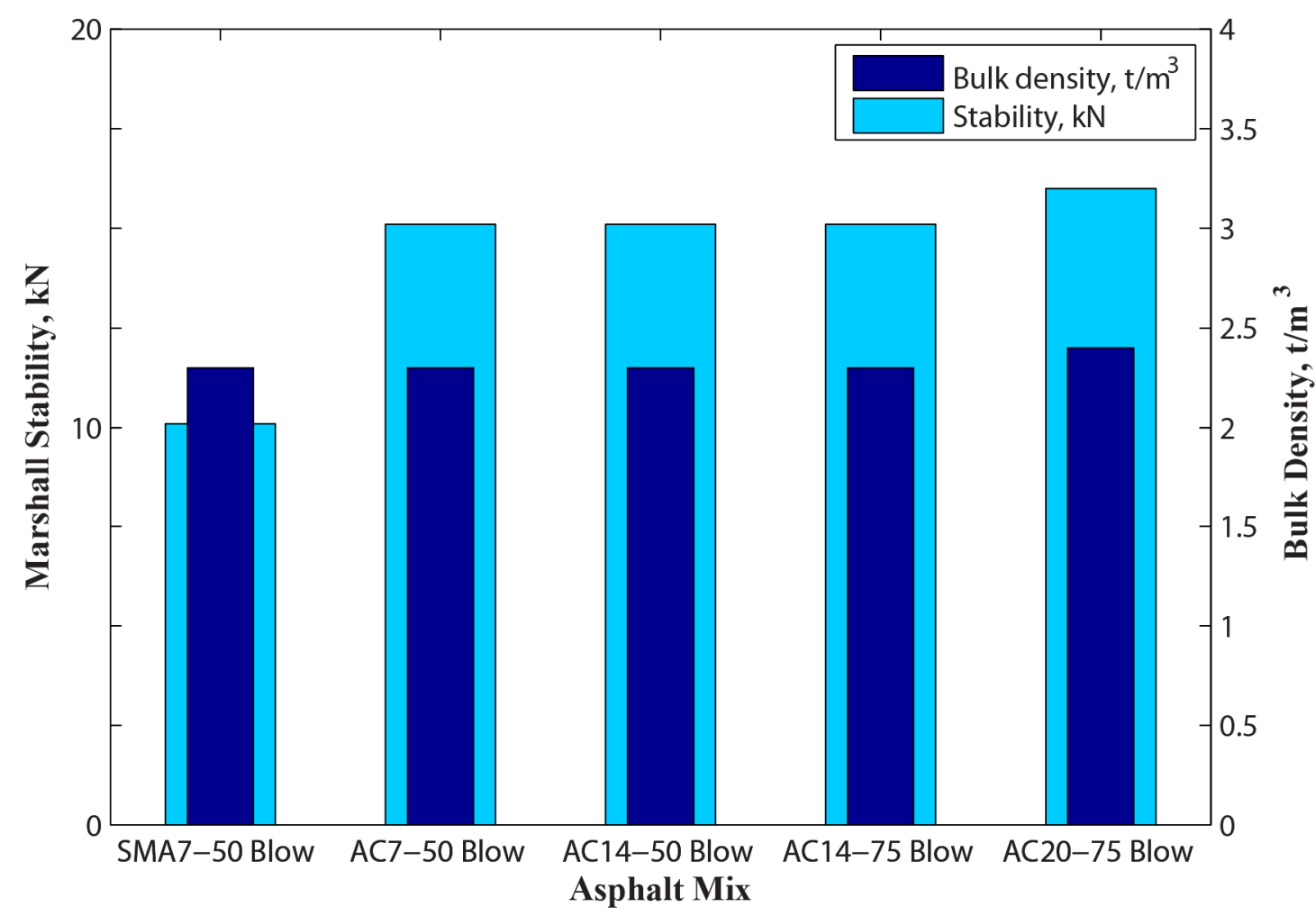

Figure 6: Average marshal compaction stability and bulk density of the different types of asphalt mixes

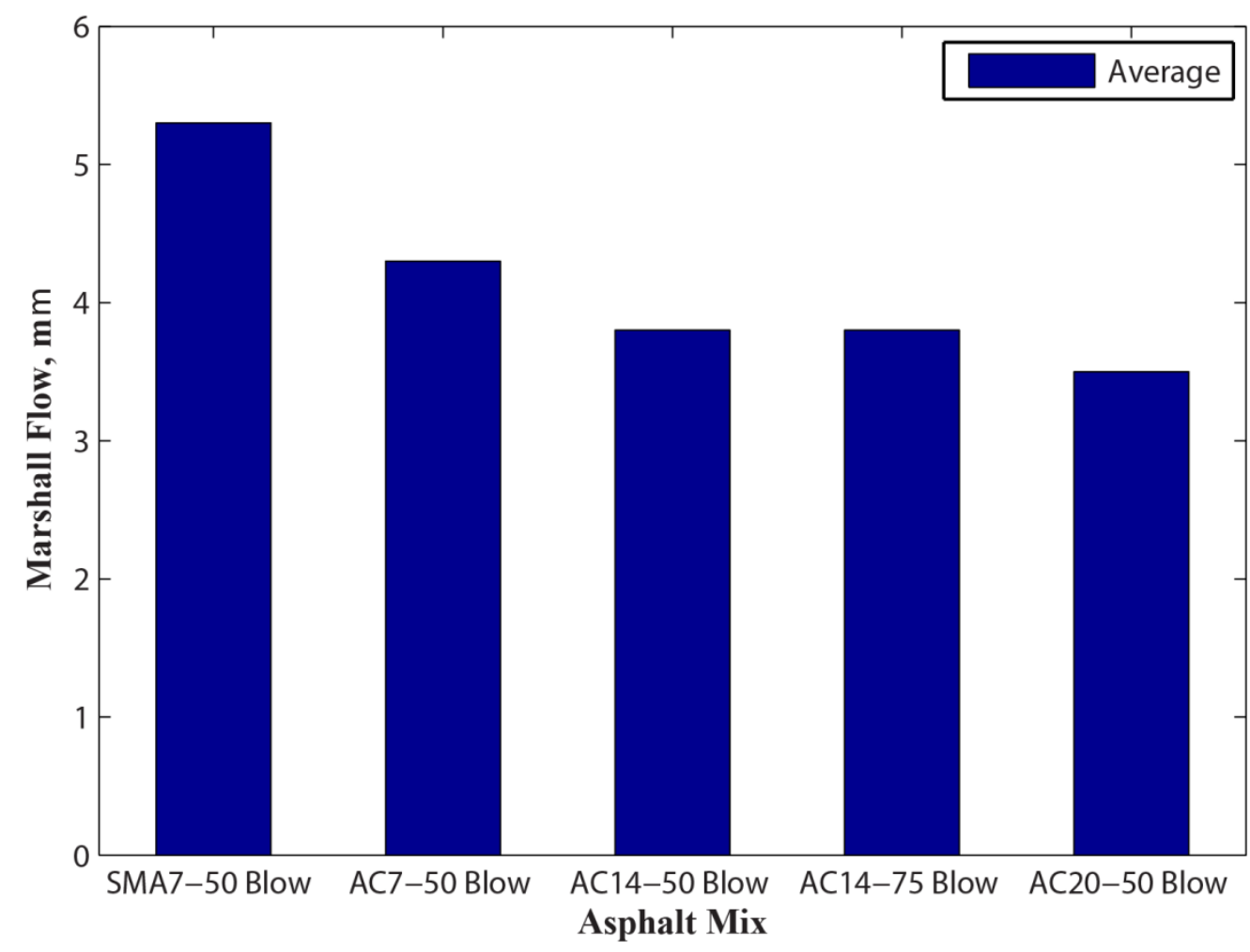

Figure 7: Comparison of Marshall Compaction flow in different types of asphalt mixes 


\section{Acknowledgement}

The financial support for this study was provided by the research project 2011/0006, entitled "Characteristics of Western Australia Asphalt Mixes" sponsored by Australia Postgraduate Awards (APA), Curtin Research Scholarship (CRS) and the Mainroads Western Australia.

The options, findings and conclusions expressed in this publication are not necessary those of Australia Postgraduate Awards, Curtin Research Scholarship or Mainroads Western Australia.

\section{References}

Airey, GD, Collop, AC, Zoorob, SE \& Elliott, RC 2008, 'The influence of aggregate, filler and bitumen on asphalt mixture moisture damage', Construction and Building Materials, vol. 22, no. 9, pp. 2015-2024.

American Association of State Highway and Transportation Officials 1986, 'Resistance of compacted bituminous mixture to misture induced damage', in Standard Specifications for Transportation Materials and Methods of Sampling and Testing, AASHTO T283, Washington, D.C.

American Association of State Highway and Transportation Officials 1993, AASHTO Guide for design of pavement structures, American Association of State Highway and Transportation Officials, Washington, DC, USA.

American Association of State Highway and Transportation Officials 2000, Resistance of compacted bituminous mixture to moisture induced damage, AASHTO T283-99, Washington, DC, USA.

American Concrete Institute Committee 2007, Aggregates for concrete, ACI Education Bulletin E1-07, American Concrete Institute, Farmington Hills, MI, USA.

Anderson, RM, Walker, DE \& Turner, PA 1999, 'Low-Temperature Evaluation of Kentucky Performance-Graded 70-22 Asphalt Binders', Transportation Research Record: Journal of the Transportation Research Board, vol. 1661, no. -1, pp. 69-74.

Apeagyei, AK, Buttlar, WG \& Dempsey, BY 2006, 'Moisture damage evaluation of asphalt mixtures using AASHTO T283 and DC(T) fracture test', in 10th International Conference on Asphalt Pavement - August 12-17,2006, International Society for Asphalt Pavements, Quebec, Canada, pp. 740-751.

Austroads 1992, A guide to the structureal design of road pavements: pavement materials, Austroads, Sydney, Australia.

Austroads 2006, Asphalt characterization of pavement design, Austroads Technical Report, AP-T63/06, Austroads, Sydney, Australia.

Austroads 2008, Testing asphalt in accordance with the Austroads mix design procedures, Austroads Technical Report, AP-T100/08, Austroads, Sydney, Australia. .

Brown, ER, Kandhal, PS \& Zhang, J 2004, 'Performance testing for hot-mix asphalt', in Transportation Research Circular E-C068: New Simple Performance Tests for Asphalt Mixes, eds C Cullather, J Correro, J Weeks \& J Awan, Transportation Research Board, Washington, DC, pp. 85-106.

Chadbourn, BA, Luoma, JA, Newcomb, DE \& Voller, VR 1996, 'Consideration of hot-mix asphalt thermal properties during compaction', in Quality management of hot-mix asphalt, ASTM STP 1299, ed. DS Decker, American Society for Testing and Materials, Minneapolis, Minnesota. 
Dibike, YB, Velickov, S, Solomatine, D \& Abbott, MB 2001, 'Model induction with support vector machines: introduction and applications', Journal of Computing in Civil Engineering, vol. 15, no. 3, pp. 208-216.

Federal Highway Administration 2002, Study of LTPP laboratory resilient modulus test data and response characteristic: final report, Report No. FHWA-RD-02-051, Federal Highway Transportation, U.S. Department of Transportation, Mclean, VA, USA.

Gillespie, TD, Karamihas, SM, Cebon, D, Sayers, MW, Nasim, MA, Hansen, W \& Ehsan, N 1992, Effects of heavy vehicle characteristics on pavement response and performance, NCHRP Final Report 1-25, Transportation Research Institue, The University of Michigan, Michigan, USA.

Gopalakrishnan, K \& Kim, S 2011, 'Support vector machines approach to HMA stiffness prediction', Journal of Engineering Mechanics, vol. 137, no. 2, pp. 138-146.

Harvey, JT, Deacon, JA, Tsai, BW \& Monismith, CL 1995, Fatigue performance of asphalt concrete mixes and its relationship to asphalt concerte pavement performance in California, Report No. RTA-65W485-2, University of California Berkeley, Calfornia, USA.

Hicks, GR \& Monismith, CL 1981, 'Factor influencing the resilient response of granular materials', in Highway Research Record 345, National Research Council, Washington, DC, pp. 15-31.

Jahromi, SG \& Khodaii, A 2009, 'Comparing factors aftecting resilient modulus in asphalt mixtures', Transaction A: Civil Engineering, vol. 16, no. 5, pp. 367-375.

Khan, ZA, Al-Abdul Wahab, HI, Asi, I \& Ramadhan, R 1998, 'Comparative study of asphalt concrete laboratory compaction methods to simulate field compaction', Construction and Building Materials, vol. 12, no. 6-7, pp. 373-384.

Linden, RN, Mahoney, JP \& Jackson, NC 1992, 'Effect of compaction on asphalt concrete performance', in Transportation Research Record No. 1217, Transportation Researh Board, National Research Council, Washington, DC, pp. 20-28.

Main Roads Western Australia 2007, Main Roads Western Australia 2007 Annual Report, Main Road Western Australia, Perth, WA, Australia, pp. 1-134.

Mrawira, DM \& Luca, J 2006, 'Effect of aggregate type, gradation, and compaction level on thermal properties of hot-mix asphalts', Canadian Journal of Civil Engineering, vol. 33, pp. 1410-1417.

Olive, JWH \& Alderson, AJ 1995a, The effect of air void content on resilient modulus, dynamic creep and wheel tracking results, ARR 272, ARRB Transport Research Ltd, Australia.

Pourtahmasb, MS \& Karim, MR 2010, 'Evaluation of the laboratory compaction effect on stone mastic asphalt mixtures', in Proceeding of Malaysian Universities Transportation Research Forum and Conference, 21 December 2010, Universiti Tenaga Nasional, Putrajaya, Malaysia pp. 411-420.

Said, SF 1997, 'Variability in roadbase layer properties conducting indirect tensile test', in Proceedings of the 8th International Conference on Asphalt Pavements, Seattle, Washington, DC, pp. 977-986.

Santucci, LE 1977, 'Thickness design procedure for asphalt and emulsified asphalt ', in Proceedings of the 4th International Conference on Structural Design of Asphalt Pavements, Ann Arbor, Michigan, USA, pp. 424-456.

Strategic Highway Research Program 1994b, Fatigue response of asphalt - aggregate mixes, SHRP A 404, Strategic Highway Research Program, Washington, D.C. 